\title{
Transient Cooling Of A Gylinder In Cross Flow Bounded By An Adiabatic Wall
}

\section{Nawaf $H$. Saeid ${ }^{1}$}

Bashir S. Abusahmin *,1

1 Mechanical Engineering Programme, Universiti Teknologi Brunei, Tungku Link, Gadong, BE 1410, Brunei Darussalam

2 Petroleum and Chemical Engineering Programme, Universiti Teknologi Brunei, Tungku Link, Gadong, BE 1410, Brunei Darussalam

*e-mail: nawaf.saeid@utb.edu.bn

The present study investigates the parameters controlling the cooling process of a cylindrical food in the storage area for a period of time. Transient analysis of the conduction and convection (conjugate) heat transfer from a cylindrical food, or a cylindrical can filled with food is selected for numerical simulations. The cylinder is bounded by an adiabatic wall and the cold air is flowing normal to the cylinder axis (cross flow). The parameters investigated are: Reynolds number, food thermal properties (density, specific heat and thermal conductivity) and the cooling period. The range of the Reynolds number is selected from 50 to 500 to be in laminar flow conditions. Three different materials were selected according their thermal properties. The results are presented to show the cooling process starting from blowing cold air stream on the cylinder for a period of 4 hours. The results show that the food with low thermal inertia is cooled faster than that of high thermal inertia. The present results show also that the cooling process can be shortened by increasing the air velocity and lower its temperature.

Keywords: Computational fluid dynamics, Transient analysis, Conjugate heat transfer, Circular cylindrical, Cross flow, Thermal inertia.

\section{INTRODUCTION}

Agricultural products can be preserved with their desirable characteristics by controlling the temperature and humidity of the air inside the storage area for a period of time. The quality of the agricultural products is related to the uniform cooling and humidification, especially during long-term storage. Usually pre-storage treatment includes cooling the food to low temperature in most of food engineering operations. The cold store is used to store different products and different periods and the uniform air conditions are difficult to attain in the industrial food storage rooms. Non uniform cooling causes either increasing the respiration at high air temperature or chilling (in sometimes freezing) at low air temperature.

The literature review shows a vast use of computational fluid dynamics (CFD) techniques in the agricultural products storage and processing industry. The computational fluid dynamics can be used 


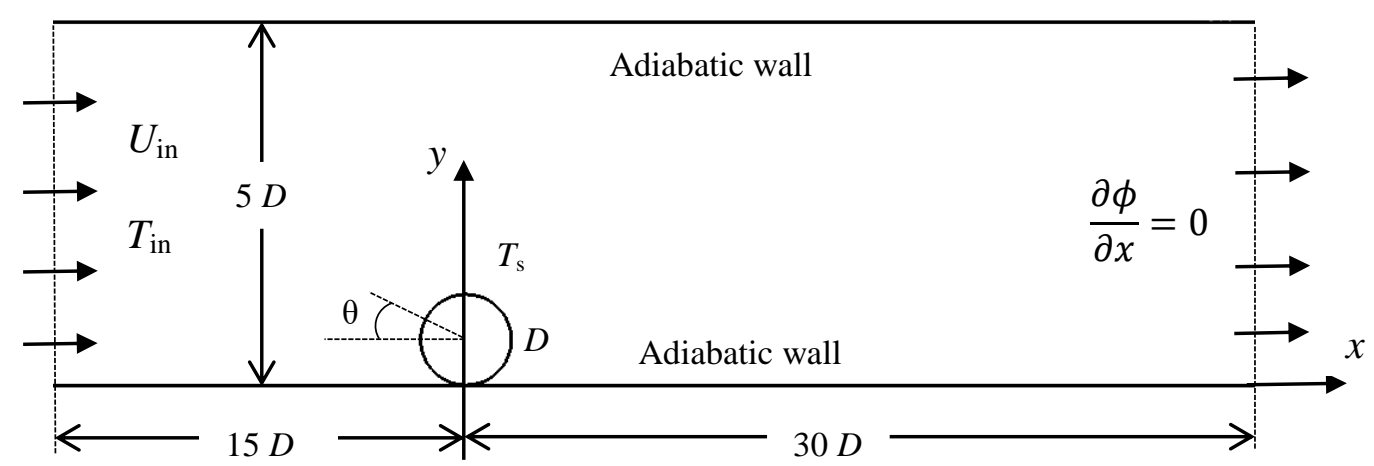

Fig. 1: The physical model and coordinate geometry

to model and numerically simulate the heat and mass transfer in this complicated geometry for the design optimization. CFD has been used in the recent years in many food processing and storage industry. Review articles can be found in the following references (Wang and Sun, 2003, Norton et al, 2007, Dehghannya et al, 2010, Lemus-Mondaca et al (2011), Ambaw et al, 2013).

The heat transfer and flow structure across non-bounded circular cylinders (suspended in a stream of fluid) is studied extensively due to its importance in many industrial applications. Literatures concerning convective heat transfer from circular cylinder in cross flow are available in abundance. Representative studies in this area may be found in the books by Sumer and Fredsoe (1997) and Zdravkovich (1997, 2003) and many review articles, for examples: Coutanceau and Defaye (1991) and Williamson (1996), Norberg, (2003) and Sumnern (2010).

It is noticed from the literature review that the heat transfer and flow structure across circular cylinder bounded by a wall is not considered for investigation. There many applications in for example cooling of cylindrical food placed on a surface by blowing cold are normal to its axis. Motivated by the lack on such important analysis, the objective of the present study is to analyse the parameters effecting the transient conjugate cooling of a cylindrical food bounded by adiabatic surface using the numerical simulation. Figure $\mathbf{1}$ show the physical model and the coordinate geometry of the present problem.

\section{MATHEMATICAL MODEL}

The mathematical model of a conjugate heat transfer is describing the conduction heat transfer through a solid body and the fluid flowing around or inside it. The heat and mass transfer in the cooling of agriculture products is a conjugate heat transfer phenomenon. It is important to investigate the cooling parameter affecting the quality of the products during the storage period.

In the present study the cooling fluid is assumed to be air as incompressible (constant density) with constant properties, and the buoyancy effect was neglected. It is assumed that the length of the cylinder is much greater than its diameter and therefore the cooling process can be modelled in two dimensions across the 
cylinder. The height of the duct is assumed 5 times the diameter of the cylinder so that the wall effects of the duct can be neglected. Similarly, the dimensions of the upstream and downstream distances shown in Figure 1 are kept much larger than the cylinder diameter to justify correct implementation of the boundary conditions at the inlet and outlet. Therefore, the governing equations for the present transient conjugate heat transfer are:

$$
\begin{aligned}
& \nabla \cdot \vec{V}=0 \\
& \frac{\partial(\rho u)}{\partial t}+\nabla \cdot(\rho u \vec{V})-\nabla \cdot(\mu \nabla u)=-\frac{\partial p}{\partial x} \\
& \frac{\partial(\rho v)}{\partial t}+\nabla \cdot(\rho v \vec{V})-\nabla \cdot(\mu \nabla v)=-\frac{\partial p}{\partial y} \\
& \rho c_{p} \frac{\partial T}{\partial t}+\rho c_{p} \nabla \cdot(\vec{V} T)-\nabla \cdot(k \nabla T)=0
\end{aligned}
$$

where $\vec{V}$ is the velocity vector which has the components $u$ and $v$ in the $x$ and $y$ directions respectively. The heat diffusion equation for the solid food is:

$$
\left(\rho c_{p}\right)_{s} \frac{\partial T_{s}}{\partial t}-\nabla \cdot\left(k_{s} \nabla T_{s}\right)=0
$$

where subscript $s$ stands for the solid cylinder. No slip (zero velocity) boundary condition is imposed on all solid surfaces. The duct walls are assumed adiabatic (thermally insulated) while coupled thermal boundary condition is imposed on the food surface. Mathematically it is represented as:

$$
\begin{aligned}
& k_{s}\left(n . \nabla T_{s}\right)=k(n . \nabla T) \\
& T_{s}=T
\end{aligned}
$$

where $n$ is the normal direction to the solidfluid interface. At the inlet, uniform velocity and temperature $\left(U_{\text {in }}\right.$ and $\left.T_{\text {in }}\right)$ of the air are defined at the inlet boundary. At the outlet, zero diffusion flux normal to the outflow boundary for all variables is imposed as indicated in Figure 1.

Air is used as working fluid to cool the cylindrical food. Three cylindrical materials are considered in the present study. The physical properties of air and the cylindrical materials are considered constants as listed in Table 1.

\section{NUMERICAL SCHEME}

The governing equations (equations (1)(5)) subjected to the boundary conditions, specified in the mathematical model, are

Table 1. Physical properties of air and cylindrical materials

\begin{tabular}{lcccc}
\hline Property & Air & $\begin{array}{c}\text { Wood } \\
\text { Suleiman et } \\
\text { al (1999) }\end{array}$ & $\begin{array}{c}\text { Cucumber } \\
\text { Fasina and } \\
\text { Fleming (2001) }\end{array}$ & $\begin{array}{c}\text { Meat } \\
\text { Marcotte and } \\
\text { Taherian (2005) }\end{array}$ \\
\hline $\begin{array}{l}\text { density } \rho\left(\mathrm{kg} / \mathrm{m}^{3}\right) \\
\text { specific heat } c_{p}(\mathrm{~J} / \mathrm{kgK})\end{array}$ & 1.225 & 543 & 959 & 1020 \\
thermal conductivity $k$ & 1006 & 1080 & 4040 & 3115 \\
$(\mathrm{~W} / \mathrm{mK})$ & 0.0242 & 0.29 & 0.61 & 0.37 \\
Viscosity $\mu(\mathrm{kg} / \mathrm{ms})$ & $1.789 \times 10^{-5}$ & - & - & - \\
\hline
\end{tabular}




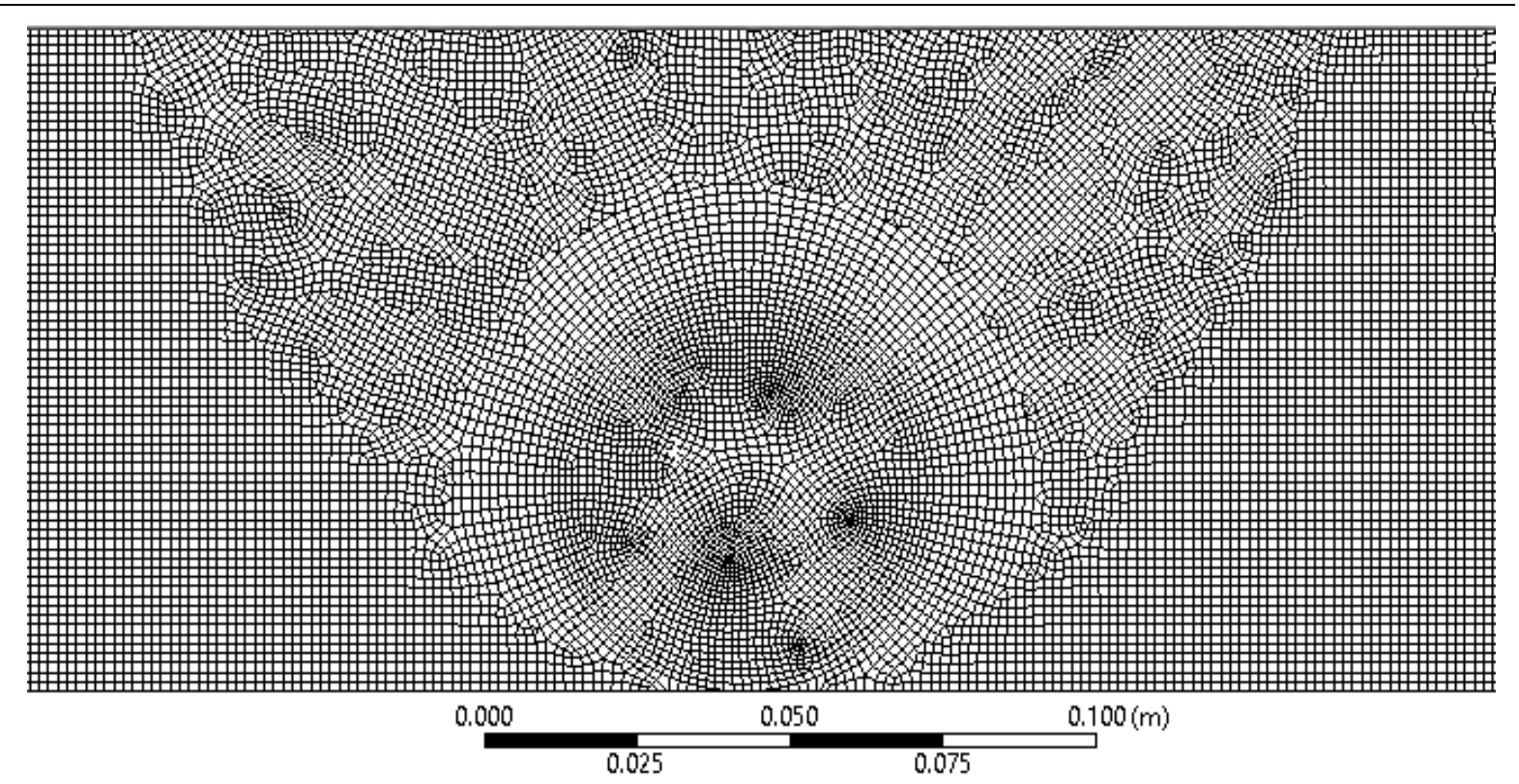

Fig. 2: Mesh geometry in the Vicinity of the Cylinder (total mesh size 417209 cells)

solved numerically using the finite volume method (Patankar 1980) build in ANSYS (20011) software. This method is based on the discretization of the solution domain into finite number of control volumes (or cells) and integrates the governing equations over each control volume. Therefore the solution domain is discretised (meshed) by dividing it into uniform quadrilateral cells. Unstructured mesh is generated using ANSYS (2011) so that the mesh cells faces are aligned with the solid-fluid interface for accurate implementation of the condition $6(\mathrm{~b})$. The mesh geometry in the vicinity of the cylinder is shown in Figure 2.

The time discretization scheme is implicit with first order accuracy with 30 seconds time step. For the spatial discretization, the least squares cellbased gradient evaluation is used where the dependent variables are assumed to vary linearly between the cells centres. The central differencing scheme is used to approximate the diffusion terms of the energy equation as well as for the momentum equations. The second order upwind scheme is used for the convectiondiffusion terms formulation of the momentum and energy equations. The discretized equations were solved based on the pressure-based coupled algorithm which solves a coupled system of equations comprising the momentum equations and the pressure-based continuity equation ANSYS (2011). This method is based on the iterative solution and the recommended values of the explicit relaxation factors for momentum and pressure are 0.75 and the flow Courant number is 200 (ANSYS, 2011). The convergence criterion is based on the residual in the governing equations. The maximum residual in the energy equation was $10^{-7}$ and the residual of other variables were lower than $10^{-6}$ in the converged solution. In all the computational cases the global heat and mass balance are satisfied in the converged solution within $\pm 10^{-3} \%$. 


\section{RESULTS AND DISCUSSION}

The velocity and thermal fields generated in the numerical solution are used to evaluate the performance of the cooling of the circular cylinder. The convection process is evaluated based on the Nusselt number. The Nusselt number is calculated using the cylinder diameter $D$ as the characteristic length. Therefore the Nusselt number can be defined as:

$$
N u_{\theta}=\frac{-(\partial T / \partial n)_{\theta} D}{\left(T_{s \theta}-T_{\text {in }}\right)}
$$

where $(\partial T / \partial n)_{\theta}$ is the local temperature gradient at the solid-fluid interface and $T_{s \theta}$ is the cylinder surface temperature with angle $\theta$ with the horizontal as shown in Figure 1. The average Nusselt number at the cylinder wall is also calculated by the area weighted average over the cylinder circumference as follows:

$$
\overline{N u}=\frac{1}{\pi D} \int_{0}^{\pi D} N u_{\theta} d s
$$

where $s$ is the distance along the cylinder circumference. To generalize the findings of the present study, the results are presented in terms of the Reynolds number based on the cylinder diameter $\left(R e=\rho U_{i n} D / \mu\right)$.

The effects of the number of the cells in the mesh on the accuracy of the results are tested by employing different mesh sizes and compare the results with the reference values. Due to lack of benchmark results (experimental or numerical) of the current problem, the results of the heat transfer from a non-bounded isothermal circular cylinder are used to validate the present results. Table 2 listed the present results of the average Nusselt number around the cylinder with referenced values of the same flow across non-bounded circular cylinder.

The results presented in Table 2 indicate that the values of the average Nusselt number for the non-bounded circular cylinder are higher than the respective values of the present simulations case. Table 2 shows also that the mesh with 417 209 cells is suitable for the simulation as the differences in the calculated values of Nusselt number are small by approximately doubling the total number of cells in the mesh. Therefore the mesh with 417209

Table 2. Comparison of the average Nusselt number

\begin{tabular}{cccccccc}
\hline & \multicolumn{3}{c}{ Non-bounded circular cylinder } & \multicolumn{3}{c}{ Circular cylinder bounded with } \\
adiabatic wall
\end{tabular}




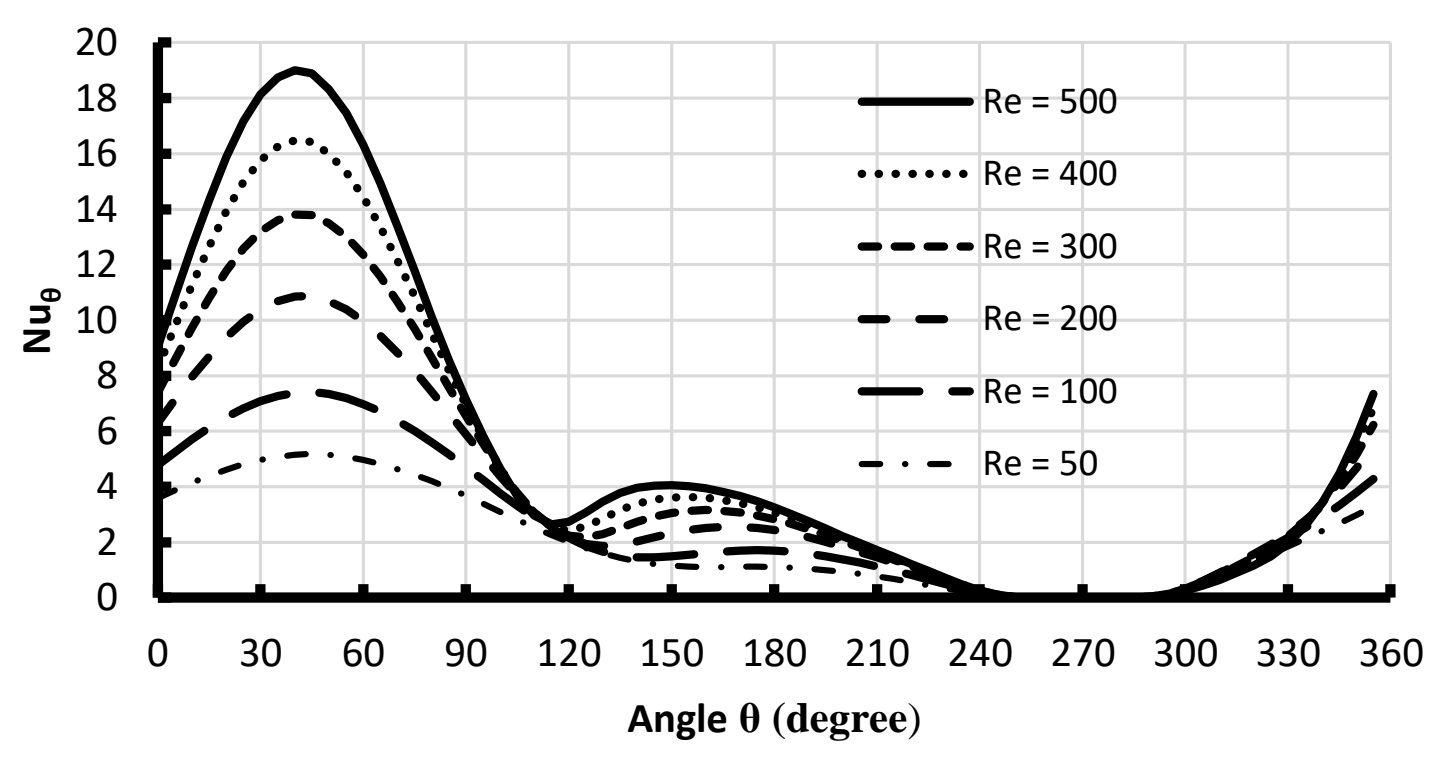

Fig. 3: Variation of $N u_{\theta}$ for steady flow across isothermal horizontal cylinder

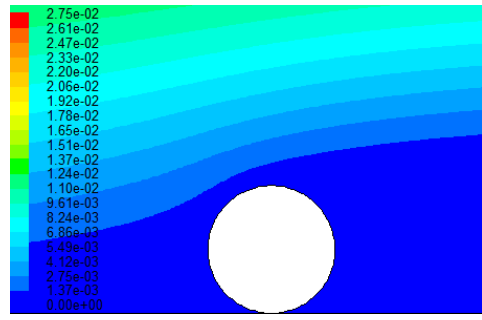

(a) streamlines $(\mathrm{kg} / \mathrm{s})$;

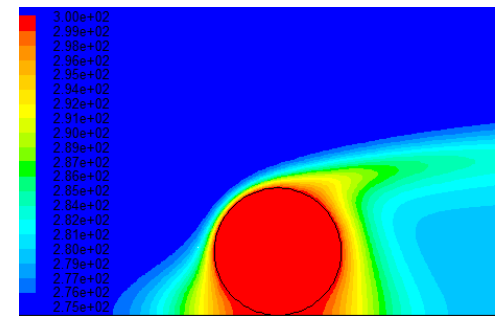

(b) isotherms (K)

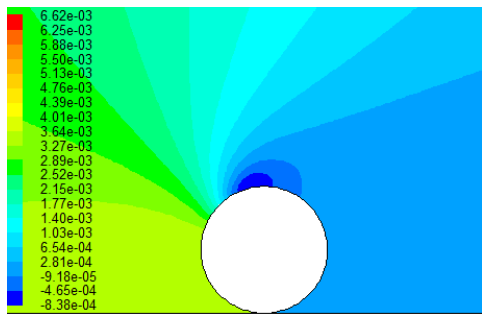

(c) static pressure contours

(Pa)

Fig. 4: Contours plot of the flow around the isothermal cylinder at $300 \mathrm{~K}$ and $\operatorname{Re}=300$

cells will be used to generate the results in the present study.

The variation of the local Nusselt number of the baseline case, steady flow across isothermal horizontal cylinder bonded by an adiabatic wall, is presented in Figure 3. The respective average values of the Nusselt number are listed in Table 2.

Figure 3 shows the maximum value of the local Nusselt number at $\theta=40^{\circ}$ which is unlike the case of the non-bounded circular cylinder where the maximum $\mathrm{Nu}$ is happening at $\theta=0^{\circ}$ due to the presence of the bounded surface. Figure 3 also shows the minimum value of the local Nusselt number $N u_{\theta}=0$ at $\theta=270^{\circ}$ which is the contact point with the adiabatic boundary wall. The results presented in Figure $\mathbf{3}$ show similar variation of $N u_{\theta}$ for the cases with different values of Reynolds numbers. Higher values of $N u_{\theta}$ are obtained in the cases of the flow with high Reynolds number.

The details of the flow around the cylinder for the case of maintaining the cylinder at constant temperature of $300 \mathrm{~K}$ and blowing air with moderate Reynolds number $(\operatorname{Re}=300)$ is shown in Figure 4 . It is clear from the streamlines that the stagnation point is not the front surface of the cylinder $\left(\theta=0^{\circ}\right)$ rather than it is at an angle around $\theta=40^{\circ}$. The isotherms also 
show that the maximum clustering isotherms are at around $\theta=40^{\circ}$ which results in maximum value of Nuessult number. The static pressure contours indicate the high pressure at this point at $\theta=40^{\circ}$ and negative pressure behind the cylinder which leads to fluid circulation in the wake region of the cylinder. The results presented in Figure $\mathbf{3}$ indicate that similar flow structure is expected at different values of Reynolds number.

To investigate the transient effects on the cooling of the cylinder, the results are generated with constant initial conditions for all the cases as: at time $=0$, the cylinder and the air in the duct is at $300 \mathrm{~K}$ and the air at the inlet is at $275 \mathrm{~K}$ and the inlet velocity value is calculated from the respective value of the Reynolds number of the considered case. The simulations are carried out on the three solid cylinders listed in Table 1. In these cases the cylinder surface is not isothermal and its temperature depends on the cooling time.

Figure $\mathbf{5}$ depicted the isotherms near the cylinder made of soft wood at different time steps and Reynolds number. The results presented in Figure $\mathbf{5}$ indicate that the cooling period needs to be increased for the low Reynolds number flow. It is obvious as the Reynolds number is increased by increasing the inlet air velocity and keeping other parameters fixed.

It is observed that the cylinder temperature near the stagnation point $\theta=$ $40^{\circ}$ is the lowest while the cylinder temperature near the contact point with the adiabatic wall $\theta=270^{\circ}$ is the highest. This observation is valid for the other cylinders made of meat and cucumber as shown in Figure 6 where the isotherms near the cylinders are presented after 4

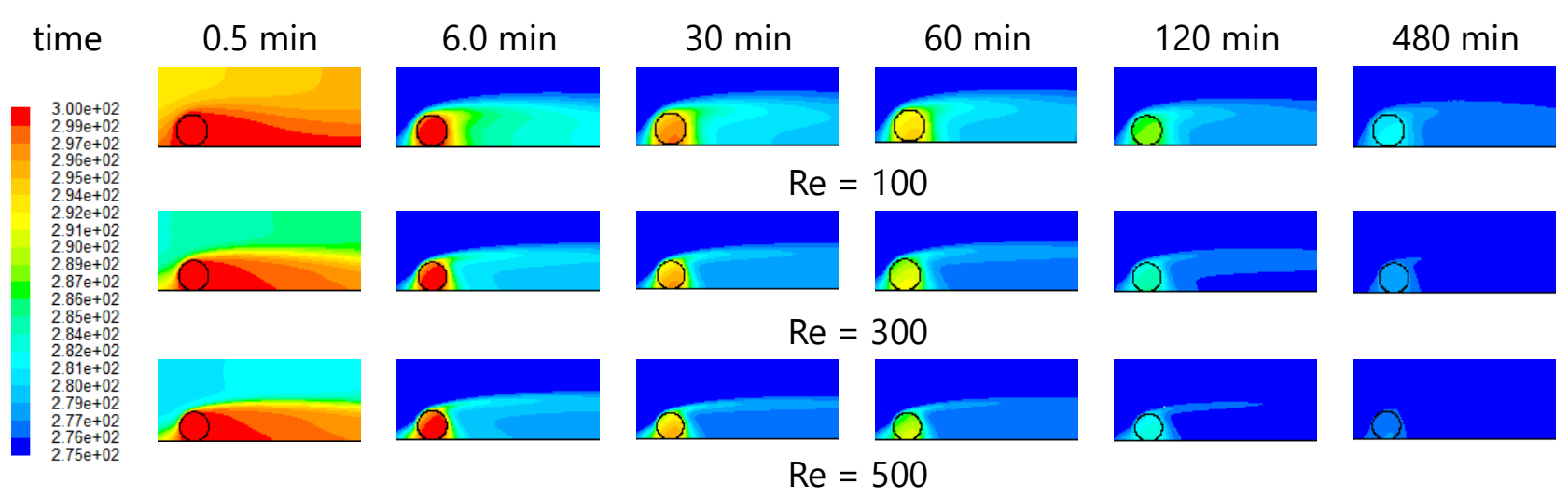

Fig. 5: Isotherms $(K)$ near the cylinder made of wood
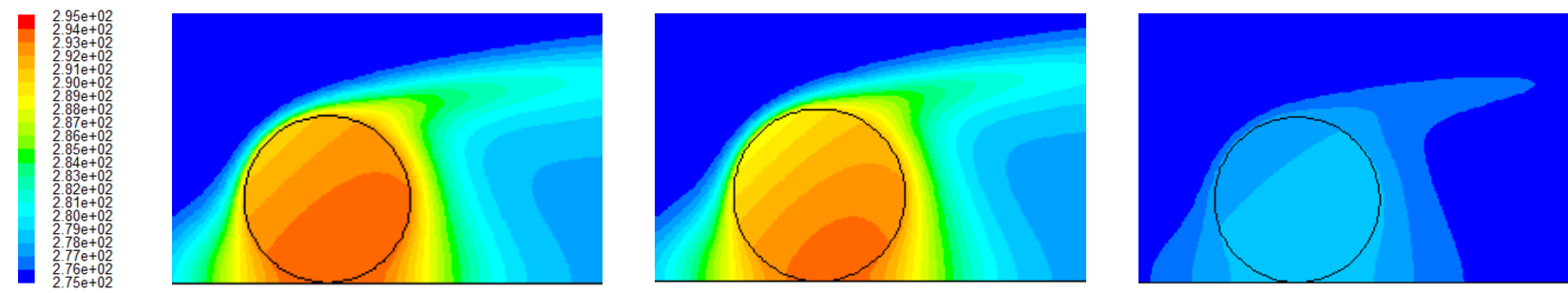

Fig. 6: Isotherms $(K)$ near the cylinders after 4 hours of cooling by air at $R e=300$. Cucumber (left), meat (middle), wood (right) 


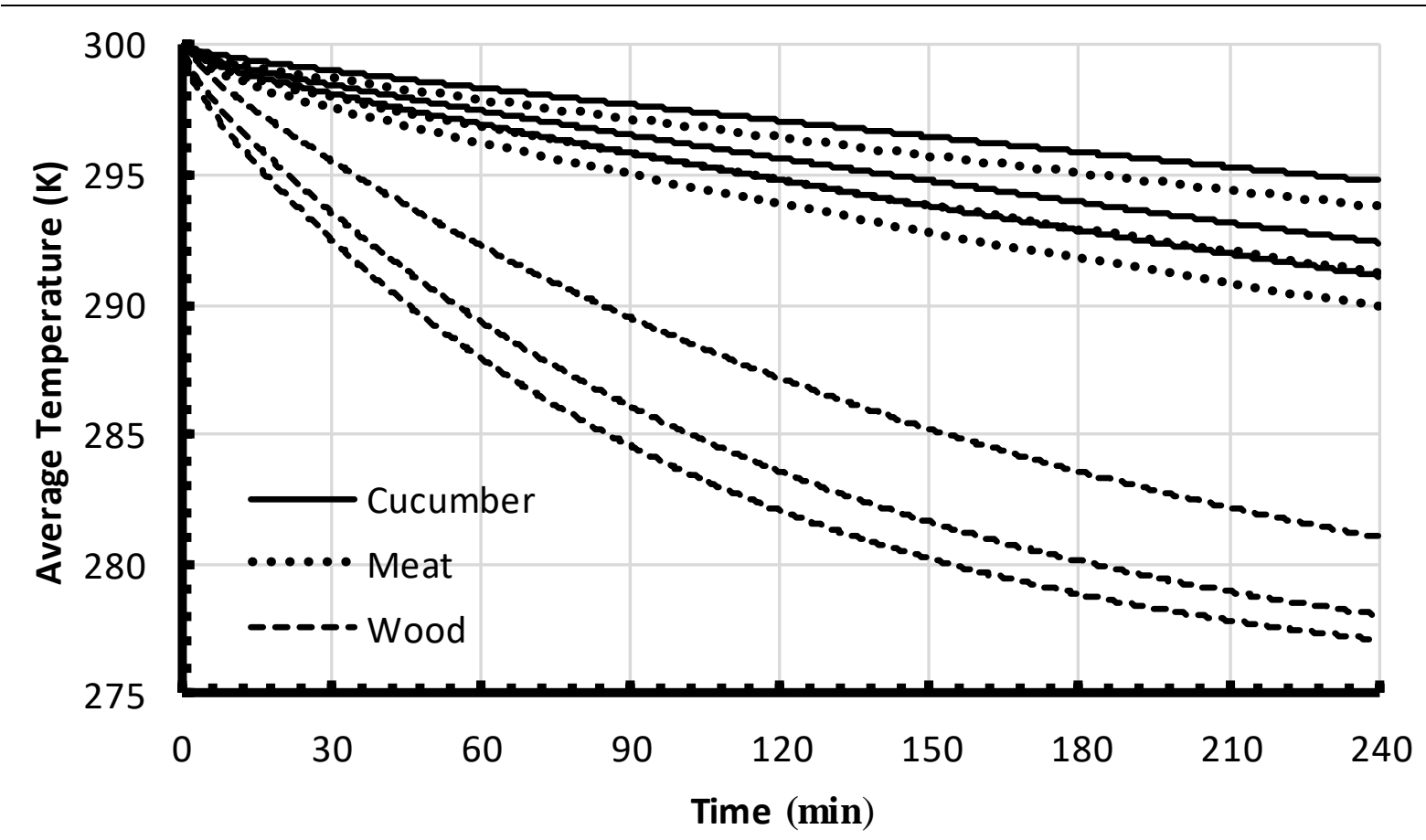

Fig. 7: Variation of the area weighted average temperature at the cylinder wall with cooling time (upper $\operatorname{Re}=100$; middle $\operatorname{Re}=300$; lower $\operatorname{Re}=500$ )

hours of cooling by air at $\operatorname{Re}=300$.

Finally the area weighted average temperature at the cylinder wall is calculated as:

$$
T_{a v}=\frac{1}{\pi D} \int_{0}^{\pi D} T_{\theta} d s
$$

The results of the area weighted average temperature at the cylinder wall is plotted against the cooling time for different Reynolds number and the three materials as shown in Figure 7. The results presented in Figure 7 show that the area weighted average temperature at the cylinder wall is decreasing sharply for the cases of the cylinder made of wood compare with others for all values of Reynolds number.

This is due to the fact that the wood has low thermal inertia compare to the other two cylinders. The thermal inertia is defined
(Wang et al. 2010) as:

$$
I=\sqrt{k \rho c_{p}}
$$

Substituting the values of the materials properties listed in Table (1) in equation (10), the values of the thermal inertia of the material are: $I_{\text {wood }}=413.1922 \mathrm{Jm}^{-2} \mathrm{~K}^{-1} \mathrm{~s}^{-1 / 2}$, $I_{\text {meat }}=1084.251 \quad \mathrm{Jm}^{-2} \mathrm{~K}^{-1} \mathrm{~s}^{-1 / 2}$ and $I_{\text {cucumber }}=1537.322 \mathrm{Jm}^{-2} \mathrm{~K}^{-1} \mathrm{~s}^{-1 / 2}$. The results show also that the area weighted average temperature at the cylinder wall is reduced more with the increase of the Reynolds number. The area weighted average temperature at the cylinder wall after 4 hours of cooling with $\mathrm{Re}=500$ is reduced from $300 \mathrm{~K}$ to $277.1 \mathrm{~K}$ for the wood compare to $289.9 \mathrm{~K}$ for the meat and to $291.1 \mathrm{~K}$ for cucumber. 


\section{CONCLUSIONS}

Transient analysis of the conjugate heat transfer from a cylindrical food, or a cylindrical can filled with food is selected for numerical simulations. Cross flow on a cylinder is considered with the effect of an adiabatic boundary below the cylinder. The present parametric study considered the flowing parameters: Reynolds number, food thermal properties (density, specific heat and thermal conductivity) and the cooling period. The flow is assumed to be laminar and the three different foods were selected according their thermal properties. The cooling process started with blowing cold air on the cylinder for a period of 4 hours. The results are presented for the steady state isothermal cylinder as well as transient cooling of the nonisothermal cylinder. It is observed from the results at all Reynolds numbers and cooling times that the lowest temperature of the cylinder happed near the stagnation point and its highest temperature occurs near the contact point with the adiabatic wall. The results show that the food with low thermal inertia is losing heat in shorter time than that of high thermal inertia. The present results indicate also that increasing the air velocity and lower its temperature will lead to shorten the cooling period.

\section{NOMENCLATURE}

$c_{p}$ : specific heat at constant pressure $\left[\mathrm{J} \mathrm{kg}^{-1} \mathrm{~K}^{-1}\right]$

D : diameter [m]

$I \quad$ : thermal inertia $\left[\mathrm{J} \mathrm{m}^{-2} \mathrm{~K}^{-1} \mathrm{~s}^{-1 / 2}\right.$ ]

$k$ : thermal conductivity [ $\mathrm{W} \mathrm{m}^{-1} \mathrm{k}^{-}$ $\left.{ }^{1}\right]$

$$
\begin{aligned}
& n \text { : normal vector } \\
& N u_{\theta} \quad \text { : local Nusselt number } \\
& \overline{N u} \text { : average Nusselt number } \\
& p \text { : pressure [Pa] } \\
& \text { Re : Reynolds number } \\
& T \quad \text { : temperature [k] } \\
& t \quad: \text { time [s] } \\
& \vec{V} \quad: \quad \text { velocity vector }\left[\mathrm{m} \mathrm{s}^{-1}\right] \\
& u, v \text { : velocity component in } \mathrm{x} \text { and } \mathrm{y} \\
& \text { directions respectively }\left[\mathrm{m} \mathrm{s}^{-1}\right] \\
& x, y \quad \text { Cartesian coordinate [m] } \\
& \rho \quad: \text { density }\left[\mathrm{kg} \mathrm{m}^{-3}\right] \\
& \mu \quad: \quad \text { dynamics viscosity }\left[\mathrm{kg} \mathrm{m}^{-1} \mathrm{~s}^{-1}\right] \\
& \theta \quad: \quad \text { angle [degree] }
\end{aligned}
$$

\section{REFERENCES}

1. Ambawa, A., Delele, M.A., Defraeye, T., Ho, Q.T., Opara, L.U., Nicolai, B.M., \& Verboven, P. (2013). The use of CFD to characterize and design post-harvest storage facilities: Past, present and future, Computers and Electronics in Agriculture, 93, 184-194.

2. ANSYS FLUENT User's Guide (2011). ANSYS Inc, Southpointe 275, Technology Drive Canonsburg, PA 15317, U.S.A.

3. Coutanceau, M., \& Defaye, J. (1991). Circular cylinder wake configurations: a flow visualization survey, Applied Mechanics Reviews, 44, 255-305.

4. Dehghannya, J., Ngadi, M., \& Vigneault, C. (2010). Mathematical Modeling Procedures for Airflow, Heat and Mass Transfer During Forced Convection Cooling of Produce: A Review, Food Engineering Reviews, 2, 227-243.

5. Fasina, O.O., \& Fleming, H.P. (2001). Heat Transfer Characteristics of Cucumber during Blanching, Journal of Food Engineering, 47, 203-210. 
6. Haider, M.J., Danish, S.N., Khan, W.A., Mehdi, S. U., \& Abbasi, B.A. (2010). Heat Transfer and Fluid Flow over Circular Cylinders in Cross Flow, NUST Journal of Engineering Sciences, 3.

7. Khan, W. A., Culham J., \& Yovanovich, M. (2005). Fluid flow around and heat transfer from an infinite circular cylinder, Journal of Heat Transfer, 27, 785-790.

8. Lemus-Mondaca, R.A., Vega-Galvez, A., \& Moraga, N.O. (2011). Computational Simulation and Developments Applied to Food Thermal Processing, Food Engineering Reviews, 3, 121-135.

9. Marcotte, M., \& Taherian, A. R. (2005). Thermophysical Properties of Processed Meat and Poultry Products, AIChE Annual Meeting Conference Proceedings, Food Engineering, Physical Properties of Food session.

10. Morgan, V. (1975). The overall convective heat transfer from smooth circular cylinders, Advances in Heat Transfer, Vol.11, Academic Press, New York, 199-264.

11. Norberg, C. (2003). Fluctuating lift on a circular cylinder: review and new measurements, J. Fluids Structures, 17: $57-96$.

12. Norton, T., Sun, D.W. Grant, J. Fallon, R., \& Dodd, V. (2007). Applications of computational fluid dynamics (CFD) in the modelling and design of ventilation systems in the agricultural industry: A review, Bioresource Technology, 98, 2386-2414.

13. Patankar, S.V. (1980). Numerical Heat
Transfer and Fluid Flow, McGraw-Hill, New York, U.S.A.

14. Suleiman, B.M., Larfeldt, J., Leckner, B., \& Gustavsson, M. (1999). Thermal conductivity and diffusivity of wood, Wood Science and Technology, 33, 465473.

15. Sumer, B.M., \& Fredsoe, J. (1997). Hydrodynamics around Cylindrical Structures, World Scientific, London, UK.

16. Sumnern, D. (2010). Two circular cylinders in cross-flow: A review, Journal of Fluids and Structures, 26, 849-899.

17. Wang, J., Bras, R.L., Sivandran, G., \& Knox, R.G. (2010), A simple method for the estimation of thermal inertia, Geophysical Research Letters, 37.

18. Wang, L., \& Sun, D. (2003). Recent developments in numerical modelling of heating and cooling processes in the food industry - a review, Trends in Food Science \& Technology, Volume 14, 408423.

19. Williamson, C.H.K., (1996). Vortex dynamics in the cylinder wake, Annual Review of Fluid Mechanics, 28, 477-539.

20. Zdravkovich, M. M. (1997). Flow around Circular Cylinders: Fundamentals, vol. 1, Oxford University Press, New York, U.S.A.

21. Zdravkovich, M. M. (2003). Flow Around Circular Cylinders: Fundamentals, vol. 2, Oxford University Press, New York, U.S.A.

22. Zukauskas, A. (1972). Advances in heat transfer, 93-160, Academic Press New York, U.S.A. 